\title{
PERCEPÇÕES DE DOCENTES DO ENSINO SUPERIOR SOBRE A INCLUSÃO DE ACADÊMICOS COM DEFICIÊNCIA
}

\author{
Mircéia Rosecler Schmit * \\ Moises Romanini ${ }^{* *}$
}

\begin{abstract}
RESUMO: O objetivo desta pesquisa foi de compreender a percepção dos docentes sobre alunos com deficiência em sala de aula em relação às barreiras atitudinais e ao uso de recursos pedagógicos adaptativos. Como instrumento de coleta de dados, foi utilizado um questionário elaborado com perguntas mistas e a análise de dados foi feita por meio de uma descrição estatística e uma análise temática de conteúdo. Os resultados sobre as percepções dos docentes na inclusão de alunos com deficiência no ensino superior mostram que é necessária a conscientização sobre as barreiras atitudinais dos professores, de modo a melhorar o processo de inclusão escolar. Uma das sugestões de melhoria é uma capacitação semestral ou anual sobre a existência de barreiras atitudinais para que os docentes possam dispor de novas maneiras de atuar com as pessoas com deficiência, seja em sala de aula ou em outros ambientes sociais.
\end{abstract}

Palavras-chave: Pessoas com deficiência. Inclusão. Barreiras Atitudinais. Ensino Superior.

\section{PERCEPTIONS OF HIGHER EDUCATION TEACHERS ON THE INCLUSION OF DISABLED SCHOLARS}

\begin{abstract}
The objective of this research was to understand the perception of teachers on students with disabilities in the classroom in relation to attitudinal barriers and the use of adaptive pedagogical resources. A questionnaire was used as a data collection instrument, elaborated with mixed questions and, afterwards, data analysis was performed through a statistical description and thematic content analysis. The results on the perceptions of the teachers on the inclusion of students with disabilities in higher education show that it is necessary to raise awareness about teachers' attitudinal barriers in order to improve the process of school inclusion. One of the suggestions for improvement is a semiannual or annual training on the existence of attitudinal barriers so that teachers can learn new ways of working with people with disabilities, whether in the classroom or in other social environments.
\end{abstract}

Keywords: Disabled people. Inclusion. Attitudinal barriers. University education.

* Graduação em Psicologia na Universidade de Santa Cruz do Sul (UNISC), mirceia@,outlook.com

** Doutor em Psicologia Social e Institucional (UFRGS), Professor Adjunto do Departamento de Psicologia Social e

Institucional da Universidade Federal do Rio Grande do Sul, moisesromanini@yahoo.com.br

\begin{tabular}{|l|l|l|l|l|l}
\hline APRENDER - Cad. de Filosofia e Psic. da Educação & Vitória da Conquista & Ano XIV & n. 23 jan./jun.2020 & p. 133-152 & ja
\end{tabular}




\section{INTRODUÇÃO}

Em diversos setores públicos e/ou privados é praticamente impossível não se deparar com um indivíduo que tenha algum tipo de deficiência. Com as políticas de inclusão e de ações afirmativas, cada vez mais pessoas com deficiência (PCDs), seja congênita, adquirida ou acidental, estão nas instituições educacionais e de trabalho. Dantas (2017) afirma que, ao longo da história, as PCDs sempre foram desqualificadas e estigmatizadas socialmente por serem consideradas fora dos padrões de normalidade categorizados pela sociedade.

A Lei no 13.146, de 6 julho de 2015 (BRASIL, 2015), denominada também de Estatuto da Pessoa com Deficiência, foi instituída para assegurar os direitos da pessoa com deficiência em condições de igualdade e promover a inclusão em todos os setores da sociedade. Nessa lei, o capítulo IV trata da educação inclusiva e aponta para o aprimoramento dos sistemas educacionais, de projetos pedagógicos que garantam o atendimento educacional especializado, da adoção de medidas que ampliem o desenvolvimento acadêmico de estudantes com deficiência, dentre outros direitos. De acordo com esse Estatuto, é considerada PCD "aquela que tem impedimento de longo prazo de natureza física, mental, intelectual ou sensorial", o que impede uma plena participação na sociedade em condições de igualdade com as demais pessoas, devido à existência de barreiras físicas (BRASIL, 2015, s/p).

A Lei n ${ }^{\circ}$ 10.098, de 19 de dezembro de 2000, apresenta normas gerais e critérios de acessibilidade para as pessoas com deficiência. Essa lei estabelece condições de acessibilidade para a utilização, de modo seguro e com autonomia, dos espaços, além de eliminar as barreiras nas comunicações e barreiras arquitetônicas que podem ser urbanísticas, edificações e transportes (BRASIL, 2000).

De acordo com Silva (2012, p. 423), as barreiras atitudinais "têm como ponto de origem o olhar negativo e generalizante que a sociedade construiu historicamente acerca da deficiência e da pessoa com deficiência." A mesma autora descreveu sobre as barreiras atitudinais em 19 tipos: barreira atitudinal de substantivação (tratar a pessoa como se ela fosse toda deficiente); de rotulação; de propagação (supor que a pessoa tenha várias deficiências); de estereótipos; de generalização; de padronização (se basear numa experiência com uma PCD e generalizar essa experiência para todas as PCDs); de particularização (segregação das pessoas em função de uma dada deficiência); de rejeição; de ignorância (desconhecimento sobre a deficiência); de negação (negar o limite da PCD); de medo; de subestimação; de inferiorização da deficiência; de menos valia; de adoração do herói (supervalorização de tudo que PCD faz); de exaltação do modelo (comparar a PCD com a outra que não tem deficiência, exaltando a primeira); de compensação (favorecer ou privilegiar a PCD); de pena; e de superproteção.

Muito se fala em políticas públicas de inclusão de PCDs, o que é altamente positivo. Porém, ao conversarmos com as PCDs sobre o processo de inclusão nos diversos ambientes da sociedade, ficam 
evidentes algumas atitudes de exclusão por parte de outras pessoas. É necessário fomentar essas práticas de inclusão para que sejam incorporadas pelas pessoas no cotidiano em geral.

Além das práticas pedagógicas, é preciso entender também que o preconceito deve ser abordado ao se propor a educação inclusiva, pois "as políticas, informações e orientações não são suficientes para a mudança de atitude dos educadores e dos alunos frente às minorias" (FERRARI; SEKKEL, 2007, p. 642). O preconceito produz uma falsa generalização que não condiz com a realidade externa, prejudicando os relacionamentos interpessoais. Os mesmos autores salientam a importância de uma atitude de reflexão por parte dos professores frente às diferenças, bem como o domínio de conteúdos de educação inclusiva para que ocorram efetivas adaptações pedagógicas com os alunos com deficiência.

Conforme Fleith (2011, p. 36), a Política Nacional de Educação Especial tem como metas “a superação da visão dicotômica entre educação especial e ensino regular e o deslocamento do foco da deficiência para o desenvolvimento das capacidades de todos os alunos". É essencial também articular os sistemas de ensino, isto é, com proposta pedagógica aperfeiçoada para os alunos com deficiência.

A inclusão escolar tem como características a revisão das práticas educacionais, identificação das necessidades do aluno, a disseminação de estratégias pedagógicas inclusivas, o suporte social aos docentes e um ambiente acolhedor e participativo entre os discentes (FLEITH, 2011). A mesma autora diz que é importante que o psicólogo escolar possa refletir sobre a política de inclusão e contribuir construtivamente para que as práticas sejam implementadas no ambiente educacional.

Frente ao contexto social, econômico e cultural no qual vivemos, no que se refere à inclusão do indivíduo na educação e, posteriormente ao mercado de trabalho altamente competitivo, é necessário um maior conhecimento de como se processam os modos e práticas de inclusão de alunos com deficiência no meio acadêmico. Isso implica também em entender e conhecer quais são as possíveis dificuldades, na percepção dos professores, relacionadas aos processos de inclusão, de modo a mostrar a realidade dos estudantes universitários.

Dentre os artigos pesquisados sobre o tema de alunos com deficiência, temos os autores Silva e Ferreira (2017) que realizaram um estudo sobre o uso da técnica de sombreamento no cotidiano acadêmico de um estudante cego, onde foram constatadas barreiras físicas e atitudinais. Santos e Dantas (2017) trazem o tema do estudante surdo no Ensino Superior e a sua forma de comunicação com os professores e colegas. Amorim, Medeiros Neta e Guimarães (2016) pesquisaram sobre a oferta de componentes curriculares com foco na deficiência principalmente nas áreas de educação e Libras. Guerreiro, Almeida e Filho (2014) fizeram uma pesquisa de satisfação com estudantes, sendo oito com deficiência visual, seis com deficiência física, três com deficiência auditiva e uma com dificuldades de aprendizagem. Os resultados sobre os processos de inclusão se mostraram variados para esses estudantes, mas mostrou a evidência de insatisfação com as barreiras atitudinais.

Selau, Damiani e Costa (2017) desenvolveram um estudo sobre os obstáculos que os estudantes cegos vivenciam no Ensino Superior, tendo como soluções o investimento na instituição e a adoção de 
ações pedagógicas que facilitam a inclusão destes mesmos indivíduos em sala de aula. Siqueira e Santana (2010) propõem melhorias em atitudes inclusivas para PCDs e aquisição de tecnologias assistivas no ES. Melo e Martins (2016) realizaram um estudo documental sobre os diferentes estágios de construção da política de inclusão nos países Brasil e Portugal.

Dantas (2017) aborda o tema a partir do olhar da gestão, dos professores e dos alunos com deficiência de modo a identificar e analisar as ações adotadas pela instituição a fim de garantir a permanência destes mesmos alunos no ambiente educacional. Nunes e Magalhães (2016) realizaram pesquisa em sete universidades federais brasileiras, apontando que as instituições de ensino superior estão dando atenção à inclusão de PCDs, porém o tema é recente e revela dificuldades de implantação das políticas de inclusão.

Dentre os autores acima pesquisados, poucos falaram sobre os processos pedagógicos de inclusão no Ensino Superior. Com a multiplicidade de causas, tipos e graus de deficiência dos discentes, é necessária uma maior reflexão sobre os recursos pedagógicos de inclusão com maiores possibilidades de intervenções e adaptações. Nessa direção, este artigo apresenta uma síntese dos resultados de uma pesquisa cujo objetivo principal foi o de compreender como os professores de graduação de uma Universidade Comunitária do interior do Rio Grande do Sul percebiam a inclusão de acadêmicos com deficiência.

É preciso levar em conta também que, além da necessidade de superar as dificuldades inerentes à própria deficiência, o aluno pode ter que enfrentar as consequências médicas, psicológicas e sociais da limitação física e desencadear estados depressivos (FERNANDES; SANTOS; LAMARES, 2012). Para os autores, também é necessário que os alunos com deficiência tenham como auxílio complementar um investimento no conhecimento e desenvolvimento de intervenções adequadas, proporcionando, assim, um melhor apoio psicológico.

Diante desse contexto, o tema da pesquisa que apresentamos neste artigo é a inclusão de acadêmicos com deficiência no ensino superior, principalmente no que se refere aos recursos pedagógicos de inclusão, capazes de promover as adaptações de acordo com as necessidades de cada estudante com deficiência. Dentro do contexto educacional do Ensino Superior, é possível identificar também as barreiras atitudinais existentes que possam dificultar a relação entre professor e aluno com deficiência e dificultar o processo de inclusão.

\section{MÉTODO}

O método utilizado foi uma pesquisa de levantamento com uma abordagem qualitativa. Segundo Bahia, Janissek e Lozado (2018), a pesquisa qualitativa parte de concepções mais construtivistas na constituição da realidade. Isso significa que, na pesquisa qualitativa, a teoria surge a partir de 
interpretações de uma dada realidade. Conforme Silva e Silveira (2007, p. 151), a pesquisa qualitativa se caracteriza "como compreensiva, holística, ecológica, humanista, bem adaptada para a análise minuciosa da complexidade, próxima das lógicas reais".

\section{Local e Participantes}

O local da pesquisa foi numa universidade do interior do Rio Grande do Sul. O questionário foi elaborado na Plataforma Google Forms e enviado por e-mail para todos os docentes do Ensino Superior que lecionam para algum aluno com deficiência. O e-mail foi enviado para 98 professores, sendo que 19 deles aceitaram responder ao questionário.

\section{Procedimentos e materiais de coleta}

$\mathrm{Na}$ referida universidade, houve a aprovação do comitê de ética para realização de pesquisa envolvendo seres humanos, sob registro do CAAE número 03293418.4.0000.5343. No segundo semestre de 2018, foi enviada uma carta de aceite para o Núcleo de Apoio Acadêmico (NAAC) da universidade pesquisada, devido à necessidade de o setor disponibilizar uma lista de e-mails dos professores de todos os cursos de graduação que tivessem algum aluno com deficiência, de modo que pudesse ser enviado o questionário on-line com a garantia de que os professores participantes não fossem identificados. Os $e$ mails disponibilizados pelo NAAC foram de professores que estavam lecionando para algum aluno com deficiência no segundo semestre de 2018, sendo que o questionário foi enviado on-line para estes mesmos professores no primeiro semestre de 2019.

O Termo de Consentimento foi enviado aos participantes de forma virtual, juntamente com o questionário. O participante só conseguiu acessar o questionário após concordar com a sua participação. Os critérios de inclusão na pesquisa foram presença de estudantes com deficiência nas disciplinas ministradas pelos professores.

Como instrumento de construção dos dados foi utilizado um questionário que foi inserido na Plataforma Google Forms (pesquisa de opiniões) elaborado com questões mistas (abertas e fechadas). Gerhardt e Silveira (2009) explicam que o questionário é um instrumento de coleta de dados a serem respondidas pelos participantes, sem a necessidade da presença do pesquisador.

\section{Análise e tratamento dos dados}

Como estratégia de análise de dados qualitativos foi utilizada a análise de conteúdo, que é uma técnica que se aplica à análise de textos escritos ou de qualquer comunicação oral, visual, gestual, visando compreender de modo crítico o sentido da comunicação oculta ou não (SILVA; SILVEIRA, 2007). De 
acordo com Minayo (2007, p. 304), “a Análise de Conteúdo, como técnica de tratamento de dados, possui a mesma lógica das metodologias quantitativas, uma vez que busca a interpretação cifrada do material de caráter qualitativo”. A mesma autora descreve que a análise temática consiste em fazer uma pré-análise que envolve a organização do material que vai ser analisado e fazer o seu levantamento por meio de várias leituras (leitura flutuante). Em seguida, foi realizada a exploração do material para compilar os recortes do texto, escolher as regras de contagem e, após, classificar e reunir os dados procurando organizar em categorias teóricas ou empíricas. E, por fim, foi realizado tratamento dos resultados, ou seja, de posse dos dados brutos, deve-se destacar as informações obtidas e realizar as interpretações relacionando-as com o quadro teórico (MINAYO, 2007).

Desta forma, foi realizada uma sistematização dos dados coletados através do questionário onde foram organizados e categorizados. Conforme Bahia, Janissek e Lozado (2018), a pré-análise dos dados coletados implica em rever os objetivos do estudo, ler os conteúdos obtidos e definir os critérios de análise. Posteriormente foi feito um recorte dos conteúdos que eram coerentes com os objetivos da pesquisa. Para fazer a agregação dos conteúdos, ou seja, a análise categorial será a priori e a posteriori, com base nos objetivos do estudo bem como nas perguntas norteadoras. E, por fim, foram abordados os resultados gerados sobre o fenômeno pesquisado com novas perspectivas teóricas sobre a realidade estudada.

A análise de conteúdo temática foi realizada a partir das respostas coletadas das questões abertas, sendo feito um recorte dos conteúdos coerentes com os objetivos da pesquisa. Depois da revisão dos objetivos, foram definidos os critérios de análise temática de conteúdo, o que levou a construção de três categorias: as percepções e vivências em sala de aula; adaptações pedagógicas e desafios e possibilidades para o processo de inclusão na Universidade.

\section{RESULTADOS E DISCUSSÃO}

Os dados coletados através do questionário elaborado na Plataforma Google Forms e enviado por email para os docentes da graduação que lecionam para alunos com deficiência, mostram alguns resultados relevantes sobre a realidade da universidade situada no interior do Rio Grande do Sul, de modo que servirão de base para reflexões e problematizações.

Inicialmente, chama a atenção o número reduzido de retorno por parte dos professores, sendo que dos 98 professores que receberam o documento enviado pela plataforma, apenas 19 responderam ao questionário proposto.

Nas respostas do questionário, os participantes da pesquisa foram $15(78,9 \%)$ professores do sexo feminino e $4(21,1 \%)$ do sexo masculino. A faixa etária dos professores variou entre 30 e 66 anos. Em relação às áreas de ensino, temos uma participação de 31,6\% dos professores das Ciências Biológicas e 
da Saúde e 26,3\% dos professores das Ciências Humanas. A participação dos professores das áreas de Ciências Sociais Aplicadas e Ciências Exatas da Terra e Engenharias tiveram a mesma porcentagem de $21,1 \%$.

Sobre os anos de experiência e atuação em docência, a variação das respostas dos participantes foi de 2 anos até 29 anos em sala de aula. Em relação ao conhecimento referente à legislação sobre acessibilidade, 11 professores responderam que possuíam conhecimentos sobre a temática, 4 responderam que possuíam pouco conhecimento e 4 responderam que não dispunham de conteúdos sobre acessibilidade.

Dentre os 19 professores que responderam, 5 relataram que, no primeiro semestre de 2019, não possuíam nenhum aluno com deficiência em sala de aula, mas que tiveram no semestre passado (2018/2). A lista dos professores nos foi passada quando o projeto foi encaminhado ao Comitê de Ética em Pesquisa (CEP), ainda no segundo semestre de 2018, por isso esses 5 não tinham alunos com deficiência em aula no primeiro semestre de 2019, mas consideramos que isso não prejudicou o andamento da pesquisa.

Dentre os tipos de deficiência citados pelos professores, 8 relataram que possuem alunos com deficiência visual e auditiva. Outras deficiências ou transtornos citados foram dislexia, déficit de atenção/hiperatividade, autismo, paralisia cerebral, dificuldade de locomoção, deficiência física, deficiência intelectual, transtorno mental orgânico e transtorno ansioso não especificado.

\section{As percepções e vivências em sala de aula}

Essa categoria aborda as percepções dos docentes sobre os acadêmicos com deficiência referentes às atitudes, comportamentos e aprendizados em sala de aula.

Dentre as respostas dos professores, 4 deles responderam que o aluno fez a primeira aproximação para falar sobre a própria deficiência e a necessidade de adaptação. Outros 12 professores relataram que se aproximaram dos alunos com deficiência para conversarem sobre a melhor forma de dar aula e temos os seguintes relatos de dois participantes: "Geralmente eu procuro primeiro me colocando à disposição para adequar as aulas e materiais de acordo com as necessidades de cada aluno" (Professora 14); e o outro relatou que "Normalmente a aproximação é feita pelo NAAC. Eu os procuro" (Professor 9).

Conforme Dantas (2017), é importante a implantação de núcleos de acessibilidade para transpor as barreiras físicas, de comunicação e de informação para que ocorra um atendimento educacional especializado no Ensino Superior. Segundo ele, os Núcleos de Acessibilidade devem observar aspectos referentes à infraestrutura que são os projetos urbanísticos e arquitetônicos; ofertar recursos pedagógicos acessíveis, tecnologia assistiva e profissionais de Libras; além de programa de extensão e de pesquisa visando construir uma sociedade mais inclusiva.

Outra participante da pesquisa relatou que: 
Depende muito do aluno e da deficiência. Anos atrás só tínhamos conhecimentos da existência de alunos com deficiências quando as aulas começavam e encontrávamos o aluno em sala de aula. O que forçava uma aproximação do aluno para entender e tentar buscar formas de trabalho. Ultimamente chegamos em sala de aula cientes que teremos alunos com deficiências e de modo geral qual a deficiência que iremos encontrar. (Professora 10).

Conforme o relato anterior, a aproximação vai depender do aluno e do tipo de deficiência que ele tem. O fato de os professores estarem mais cientes hoje sobre as deficiências de seus alunos é devido as intervenções do NAAC, existente nesta Universidade. Existe também a questão da dificuldade de os discentes se aproximarem dos docentes devido à dificuldade de locomoção como, por exemplo, os cadeirantes e os que têm a deficiência visual, expressos na seguinte fala: "Os alunos com deficiência motora normalmente não me procuram para conversar. No caso de um aluno com deficiência visual, eu me aproximei primeiro, para entender as dificuldades e como seriam os melhores meios de acessibilidade aos materiais de aula" (Professora 7). Selau, Damiani e Costas (2017, p. 437) falam da importância de “dialogar com o aluno cego sobre as possíveis formas de estabelecer a relação professor-conteúdo-aluno, previamente ao ensino dos conteúdos”.

Em relação à comunicação do aluno sobre a própria deficiência, 4 professores relataram que não receberam nenhuma informação. A seguir transcrevo alguns relatos: "Não, pois no momento em que abordo, os alunos agradecem e não entram em maiores detalhes, o que eu acabo respeitando" (Professora 14); ou "Já tive casos que relataram, mas a maioria não" (Professora 3); e um outro respondeu que: "Não me relatou. Recebi as orientações previamente do NAAC” (Professor 4). Para Santos e Dantas (2017, p. 510), "na perspectiva de relacionamento, o estudante diz ter um bom relacionamento com os colegas e professores, porém sente dificuldade em algumas situações em função da comunicação."

Outros 15 professores responderam que foram informados sobre o tipo de deficiência pelos alunos. A seguir tem um relato sobre como ocorreu essa troca de informação:

Sim. Uma das alunas cadeirantes também tinha problemas nas mãos, decorrentes de acidente de carro. Contou todas as dificuldades e necessidades de adaptação. A outra, apenas solicitou para sentar na primeira classe e para ser conduzida por alguém da família. O aluno cego manifestou suas dificuldades e necessidades de adaptação de materiais. $\mathrm{O}$ aluno disléxico apenas comentou sobre a necessidade no dia da avaliação. (Professora 12).

Conforme Dantas (2017), uma relação flexível com os professores facilita o processo de aprendizagem, pois é uma forma de os docentes perceberem mais os estudantes com deficiência e o modo como aprendem. Outra participante relatou que:

[...] Quando ele aguardava pela aula da noite semestre passado foi me contando de suas necessidades: de uma mesa especial, ajuda no elevador, mostrou como movimentava a 
cadeira, que precisava sentar bem na frente. Logo no início da aula neste semestre me disse que era ansioso, sobre o que conversamos, e falou das dificuldades na escrita, contou como estudava e quando perguntei se acessava a internet e a sala virtual disse que sim. (Professora 19).

Segundo Bortolazzo (2015, apud DANTAS, 2017, p. 54), “as relações constituídas entre estudantes e professores repercutem em seu processo de aprendizagem" e é preciso ter uma vontade de ensinar e aprender, ter uma escuta e um olhar atento ao outro. A partir dessa atitude de empatia, de se colocar no lugar do outro para conseguir entender as suas necessidades, dificuldades e facilidades, é possível flexibilizar e adaptar os recursos pedagógicos de modo que cada aluno com deficiência consiga absorver e aprender o conteúdo passado em sala de aula.

Os docentes que participaram da pesquisa descreveram como percebem seus alunos com deficiência em sala de aula como, por exemplo: "Já tive experiência com um acadêmico que se saiu melhor que o esperado, inclusive com grande participação nas aulas, e outros com desistência de cursar a disciplina" (Professora 3). A frase em que diz que o acadêmico se saiu melhor que o esperado talvez seja uma forma de "exaltação das pessoas com deficiência e a supervalorização ou superestimação de tudo o que elas fazem, porque delas se espera algo de inferior intensidade", o que se configura como uma barreira atitudinal de adoração do herói (SILVA, 2012, p. 422). A mesma autora explica essa barreira atitudinal de herói é uma das 19 barreiras atitudinais originadas por meio do olhar negativo e generalizante acerca da pessoa com deficiência. Para eliminar essa barreira atitudinal de adoração do herói, é necessária uma mudança do conceito sobre a normalidade usada pela sociedade.

Outra participante relatou que:

Percebo que há dificuldades relativas à deficiência, mas que isso não os impede de aprender e acompanhar o andamento da turma. De modo geral, todos os alunos têm alguma dificuldade, algumas físicas, outras emocionais, o que acaba interferindo no processo de aprendizagem. (Professora 14).

Atitudes por parte dos alunos como não gostar de estudar, ter problemas em aceitar a deficiência, insegurança, problemas com a comunicação social, podem dificultar a aprendizagem na educação superior (SELAU; DAMIANI; COSTAS, 2017).

Depende do aluno. A atual aluna é bem esforçada e conseguimos trabalhar bem, eu também me adequei as necessidades dela, bem tranquilo. Mas a aluna com dificuldades motoras (passado), foi horrível. Ela não aceitava as orientações e queria ser beneficiada pela sua limitação, deu até processo. (Professora 16).

No Estatuto da Pessoa com Deficiência, capítulo II, Art. 4, está expresso que "Toda pessoa com deficiência tem direito à igualdade de oportunidades como as demais pessoas e não sofrerá nenhuma espécie de discriminação" (BRASIL, 2015, s/p). Cabe aqui uma reflexão na parte em que a professora 
relata sobre o processo judicial movido pela aluna, pois quis ser beneficiada pela própria condição de deficiência, é importante salientar que os estudantes reconheçam que, além de seus direitos à educação inclusiva conforme expresso no Estatuto, existe também a questão de se cumprir os próprios deveres, como, por exemplo, mostrar-se interessado em aprender, apesar de algumas limitações impostas pela própria deficiência, sem querer tirar algum proveito desta limitação.

O processo de inclusão de pessoas com deficiência no ensino superior,

ainda se encontra marcado por indefinições sobre a forma como deve acontecer e, apesar de muitas instituições se mostrarem receptivas à chegada dessas pessoas, os pais e até mesmo os educadores ainda constatam que há o despreparo ou a falta de formação para recebê-las, gerando inseguranças em todos os atores envolvidos e partícipes do processo. (CARVALHO et al, p. 55).

É importante que se criem condições para que os alunos sejam atendidos de forma satisfatória e, para isso, "é necessário que haja a disponibilidade de recurso para a capacitação dos professores e de todos os profissionais envolvidos no processo de inclusão" (CARVALHO et al, 2017, p. 59). Conforme Dantas (2017), a didática usada pelo professor, muitas vezes, é incompatível para a especificidade da deficiência do estudante, além da falta de preparo dos docentes para perceberem as reais necessidades ou dificuldades que estes alunos apresentam.

\section{Adaptações pedagógicas}

Silva e Vinha (2014, p. 5) descrevem que a palavra adaptação é “uma forma de flexibilização, pois traz em sua essência a necessidade de alteração, ajustes ou modificações no processo de ensino no âmbito do currículo". Nesse sentido, essa categoria busca abordar o entendimento dos professores sobre a adaptação pedagógica, bem como sobre as formas como eles vêm realizando esse processo.

Os professores responderam que a adaptação pedagógica é necessária para todos os alunos, sem exceção: "Consiste em, a partir das fragilidades do processo de aprendizagem de determinados alunos (não necessariamente estudantes com deficiência) repensar e reorganizar sua metodologia de ensino" (Professora 8). Outra participante expôs que a adaptação deve ocorrer em todos os espaços educativos, que vão além de uma sala de aula:

A adaptação pedagógica não está relacionada apenas a alunos com algum tipo de deficiência. Ela implica a possibilidade de qualquer aluno, de qualquer idade, se sentir confortável em espaços educativos, não só nas salas de aula. Evidentemente, a tarefa de fazê-lo compete a toda a comunidade escolar. (Professora 5).

Dantas (2017) comenta, a partir da literatura, sobre a atitude pedagógica de pseudotratamento igualitário como uma das barreiras de atitude, pois é preciso levar em consideração as particularidades de 
cada aluno com deficiência, para adequar de forma satisfatória os recursos didáticos. Nota-se a preocupação das docentes em adequar os recursos pedagógicos aos seus alunos com deficiência: "Fazer o melhor para que o aluno apreenda, e isso envolve fazer diferente e direcionado às necessidades específicas de cada aluno" (Professora 16). Outra professora colocou que:

Compreendo como um cuidado com alunos com deficiência em que se considere suas particularidades sem descuidar do processo pedagógico como um todo, daquilo que é esperado para o grupo de alunos em determinada disciplina, no que concerne a métodos, conteúdos, avaliações. Se fosse possível trabalhar mais concretamente a partir de suas realidades, seria bem interessante. Ainda temos adaptações limitadas para alunos com deficiência, pois há falta ou pouca qualidade de recursos de acessibilidade. Apesar de haver suporte do NAAC para textos e de nos orientarem sobre como fazer as adaptações, é difícil produzir recursos novos rapidamente. [...] Coloco-me no lugar do aluno e sinto o quanto é necessário se esforçar para manter-se incluído. (Professora 19).

Dantas (2017) descreve também que o fracasso escolar dos alunos com deficiência decorre geralmente da falta de adaptação pedagógica quando os docentes não estão preparados para lecionarem para estes mesmos alunos. Complementa que algumas pessoas acreditam que "o fracasso escolar decorre da deficiência, o que pode não ser correto, visto que, sem adaptação, alguns alunos podem não ter contato com a matéria exposta pelo docente" (p. 48).

Os docentes foram questionados sobre como estão vivenciando as adaptações pedagógicas atuais, sendo que alguns relataram algumas dificuldades e outras nem tanto como se vê na resposta desta participante: "Mudando, repetindo, mudando novamente, exercitando o desapego e a capacidade maravilhosa que o humano possui de adaptar-se” (Professora 5). Outra docente diz que o apoio que recebe é o suficiente: “O NAAC me assessora e tem sido suficiente” (Professora 18).

A partir do que o NAAC orienta, num primeiro momento. Conversando com colegas e ouvindo sua experiência. E, o que é mais rico, vivenciando a aula com esses alunos. Neste semestre tenho buscado de diferentes formas melhorar o processo com o aluno citado acima, mas percebo que tenho limitações em como ensinar e como trabalhar com o grupo. Em outros momentos houve o entrosamento de todos, desde o início, agora tenho usado diferentes estratégias. (Professora 19).

Os conflitos entre aprendizagem, capacitação docente e adaptação ao ensino têm gerado novas situações às IES que há duas décadas eram circunstanciais ou esporádicas (SILVA, 2014, p. 417).

Substituí provas por oficinas de discussão em aula (no caso do aluno com deficiência visual, eu enviava a ele os mesmos artigos/reportagens em áudio), estudos de caso em grupos e avaliações em formato de "quiz" oral. Desse modo, todos os alunos participavam, propiciando a inclusão de uma forma natural, e não "forçada". As atividades, que também prestigiam metodologias ativas, tiveram aproveitamento superior ao de provas comuns, e, portanto, seguem sendo adotadas por mim em outras disciplinas e em semestres subsequentes. (Professora 7). 
No Estatuto da Pessoa com Deficiência, capítulo IV, o Art. $27^{\circ}$ expõe sobre o direito a educação da pessoa com deficiência que proporcione "aprendizado ao longo de toda a vida, de forma a alcançar o máximo desenvolvimento possível de seus talentos e habilidades físicas, sensoriais, intelectuais e sociais, segundo suas características, interesses e necessidades de aprendizagem” (BRASIL, 2015, s/p).

Penso a respeito quando acontece, considerando as limitações apresentadas pelo aluno. Nos casos que tive, prestei muita atenção nas explicações, exemplificando mais do que o normal, me aproximando e perguntado se tinha entendido. Não tive casos de deficiência visual, e sim casos de hiperatividade, audição, autismo e déficit de atenção. (Professora 3).

Já o Art. $28^{\circ}$ do mesmo Estatuto descreve sobre como implementar projeto pedagógico que atenda às características dos estudantes com deficiência para garantir a aprendizagem em condições de igualdade, além de planejamento e elaboração de plano de atendimento educacional especializado para facilitar e organizar os recursos pedagógicos específicos para cada aluno com deficiência. (BRASIL, 2015, s/p). O relato a seguir expõe que estão ocorrendo atrasos na entrega de textos para um estudante com deficiência visual:

A aluna com deficiência visual tem me tirado o sono, o NAAC me informou que a aluna estaria em duas disciplinas minhas na semana das aulas, meus textos de apoio são longos, e eles pedem pelo menos um mês para adaptar, ou seja, ela está recebendo os textos com atraso e ainda não é bem adaptada com o leitor. Não tenho dúvidas da capacidade dela, mas não seria justo aplicar uma avaliação igual, pretendo conversar com ela sobre o assunto. (Professora 15).

A questão que fica é: como pode ser melhorada essa situação para que não ocorra mais os atrasos na entrega dos materiais, de modo que facilite as adaptações pedagógicas para a estudante e que seja mais condizente com que diz no $\mathrm{Art}^{\mathrm{o}} 28$ do Estatuto citado anteriormente? Não se trata de criticar ou desmerecer alguém, mas de pensar em soluções mais viáveis de adaptações para que tanto a aluna e a professora se sintam confortáveis e acolhidas em seus respectivos papéis dentro da universidade. Para Selau, Damiani e Costas (2017), é preciso ter um cuidado para que o aluno com deficiência permaneça no Ensino Superior e esse cuidado implica em um adequado projeto pedagógico inclusivo que proporcione um aprendizado de boa qualidade.

Carvalho e colaboradores (2017) apontam que a educação inclusiva ocorre quando o gestor do ensino superior investe em materiais pedagógicos apropriados, qualifica os professores, além de ficar atento a qualquer prática discriminatória. Essas atitudes de melhorias, quando postos em prática, tende a melhorar os processos de inclusão de PCDs.

$\mathrm{Na}$ concepção dos docentes, sobre se as adaptações pedagógicas estão sendo suficientes para os alunos com deficiência, quase todos responderam que são insuficientes, como se observa nos trechos das falas seguintes: "Não. Porque a inclusão é muito mais do que isso. Não basta desenvolver materiais, 
recursos e aulas adaptadas. O estudante precisa se sentir parte daquele contexto, estando apto a participar ativamente das atividades e interagir com os colegas" (Professora 2). Outra participante opinou que depende da boa vontade do estudante: "Não, o aluno também tem que querer aprender e se adaptar mostrando interesse" (Professora 6). Outra docente respondeu sobre a dificuldade de um aluno com deficiência visual para explicar a insuficiência da adaptação pedagógica:

\footnotetext{
Não, porque a inclusão não se esgota na sala de aula. $\mathrm{O}$ aluno com deficiência visual acabou sendo meu orientando por ocasião do TCC, e enfrentou dificuldades imensas para encontrar bibliografia, redigir o texto, enfim... Há muitas searas que extrapolam o convívio professor-aluno. (Professora 7).
}

Fica difícil para um estudante com a visão comprometida buscar material de pesquisa para o TCC (Trabalho de Conclusão de Curso), pois os mesmos são acessíveis somente para os indivíduos que possuem a visão. Para Selau, Damiani e Costas (2017, p. 437), "a preparação pedagógica para o atendimento a alunos cegos e videntes, coletivamente, começa pela reflexão sobre as concepções que se tem a respeito da cegueira". Talvez a resposta para essa problemática esteja na opinião que uma outra docente expôs sobre a importância de uma política mais clara:

A adaptação pedagógica é fundamental, mas penso que falta uma política mais clara para inclusão nos cursos de graduação e na própria universidade. [...] Quando a dificuldade que se apresenta extrapola o esperado, ou já há papéis cristalizados, estereótipos ou indefinições que deixam as pessoas, inclusive a professora, sem um norte, fica difícil incluir. (Professora 19).

Ainda assim, "as adaptações do material pedagógico, do equipamento tecnológico, dos recursos físicos, da comunicação devem ser buscadas pelos gestores institucionais e proporcionadas pelos professores, para mediar o aprendizado dos conteúdos científicos” dos estudantes (SELAU; DAMIANI; COSTAS, 2017, p. 436). Apesar disso, uma professora expôs que "Depende do caso e da adaptação. Como não tenho preparação para atuar com situações especiais, acredito que as adaptações que foram feitas, não foram suficientes em todos os casos” (Professora 12). Outra docente colocou a importância do NAAC na inclusão dos acadêmicos com deficiência: "Acredito que sim, pois o NAAC vem acompanhando o trabalho e as dificuldades dos professores, orientando-os na confecção dos conteúdos e dos materiais instrucionais" (Professora 17).

Conforme Dantas (2017), o professor possui ainda dificuldades em compartilhar seus conhecimentos e suas ignorâncias, o que dificulta a inclusão. Comenta também sobre a falta de material didático para trabalhar com estudante com deficiência, além da importância de atuar em prol de uma construção mais abrangente das práticas pedagógicas. A docente expôs uma realidade que vai além de uma adaptação pedagógica: 
[...] a inclusão é processo que transcende uma adaptação pedagógica. Inclusão não é sinônimo de assistencialismo. Entendo que promovemos aqui na instituição muito mais acessibilidade dos alunos com deficiência ao ensino e, com isso, não promovemos a inclusão. Esta também é gerida a partir de políticas públicas e, na instituição, de debates e momentos de discussão, o que são raros. Existe um núcleo de apoio, mas que, no meu entendimento, promove muito mais acessibilidade e apoio ao professor na condução em sala de aula. Inclusão transcende a isso. (Professora 13).

Carvalho e colaboradores (2017) explicam que, para ocorrer uma verdadeira educação inclusiva, é importante que ocorra uma reestruturação das práticas pedagógicas nas universidades que proporcionem o aprendizado para todos, buscando promover também a inclusão social. Dantas (2017) descreve que a falta de conhecimento básico das características de cada deficiência por parte dos professores é um agravante que dificulta o uso de recursos pedagógicos voltados aos alunos da área da Educação Inclusiva

\section{Desafios e possibilidades para o processo de inclusão na Universidade}

Conforme Dantas (2017, p. 58), as instituições precisam "romper com as diversas barreiras existentes em seus espaços, sejam elas físicas, comunicacionais, pedagógicas, atitudinais", criar núcleos de acessibilidade e combater as práticas de exclusão. Temos o relato da seguinte participante:

[..] Neste semestre estou sentindo dificuldade para trabalhar a integração. Por vezes quero trabalhar algo diferente e, dependendo da adaptação a ser feita, não há tempo. Sinto certa dificuldade no planejamento inicial do semestre, quando deveria preparar todo o semestre, pois recebemos na última semana antes das aulas a confirmação dos participantes da disciplina e, por e-mail, as orientações específicas. O prazo para adaptar materiais com o NAAC é bem longo (provavelmente há poucos trabalhadores) e teria que ser pensado previamente. [...] Já vivi momentos difíceis, como quando levei vídeos precariamente legendados, textos que não consegui adaptar a tempo para leitura através de programa de computador, slides que decidi incluir e não enviei com antecedência, ou quando esqueci em algum momento da aula de me dirigir adequadamente ao campo de visão ou elevar o 'volume' da fala. Como trabalhar temas complexos com alunos com déficit no processamento de informações e na capacidade de compreensão? (Professora 19).

Conforme Selau, Damiani e Costas (2017), a responsabilidade é da universidade em acompanhar sobre como os recursos pedagógicos de cada curso estão sendo utilizados e se estão proporcionando um ambiente adequado de ensino e aprendizagem. Os mesmos autores falam da importância das políticas institucionais de educação inclusiva com a proposta de vincular toda a comunidade acadêmica e repensar em ações neste sentido.

[...] é preciso passar por um processo de humanização, de nós mesmos e do outro. Acho que às vezes temos medo de enfrentar novos desafios - e, no meu caso, de ofender, sem querer, um aluno com deficiência, por usar algum termo inadequado no discurso de uma aula. Dizer, por exemplo, "vejam, aqui, pessoal", em frente a um aluno cego, e gerar um constrangimento. Mas, aos poucos, aprendemos que estabelecendo uma 
relação de confiança, isso pode ser natural, e não precisamos entrar na sala de aula nos policiando. [...] (Professora 7).

O relato anterior demonstra que a professora se empenhou em vencer uma barreira atitudinal de medo que "é quando se tem receio em fazer ou dizer algo errado diante da pessoa com deficiência" (SILVA, 2012, p. 422). Conforme Santos e Dantas (2017), vários são os desafios que os professores e alunos com deficiência enfrentam, pois necessitam desenvolver métodos adaptativos de ensino e aprendizagem no ensino superior. Os mesmos autores falam da importância e da necessidade da gestão em observar as condições de trabalho dos professores que lidam com alunos com deficiência. Complementam que a gestão precisa criar "espaços de apoio para o estudante de inclusão, investir em tecnologias assistivas, promover espaços de discussão entre gestão, docentes e estudantes" (SANTOS; DANTAS, 2017, p. 512).

Ao se deparar com dificuldades na docência com alunos com deficiência a atitude da maioria dos professores é buscar maiores informações no NAAC ou em outras fontes. A seguir tem o relato de uma professora sobre isso:

Sim, já encaminhei alunos para atendimento do NAAC. E no próprio NAAC solicito informações. Já fiz leituras sobre os assuntos de autismo, hiperatividade, por interesse e necessidade de entender o que acontece realmente com uma pessoa que apresenta isso. Conversei com pessoas que têm parentes com autismo, por curiosidade de entender todos os desafios enfrentados. (Professora 3).

Sempre é válido e relevante buscar informações sobre os tipos de deficiência, apenas tendo o cuidado de evitar a barreira atitudinal de padronização, que é "a efetivação de serviços, baseada na experiência generalizada com indivíduo ou grupos de pessoas com deficiência” (SILVA, 2012, p. 421), pois existem as particularidades e características de cada aluno com deficiência. O mesmo cuidado é válido também para a barreira atitudinal de generalização, que é “a homogeneização de pessoas baseada numa experiência interacional com um dado indivíduo ou grupo" (p. 421).

Outra docente relatou que: "Busco informações com os próprios alunos. O NAAC já entrou em contato comigo e me deu um suporte excelente.” (Professora 2). Por isso, faz-se necessário criar um ambiente favorável à inclusão com atitudes pragmáticas como elaborar estratégias didáticas inclusivas, mudanças de atitudes sociais, formar e informar profissionais no sistema educacional e solidificar práticas de políticas inclusivas. O processo de inclusão não ocorre de forma tranquila, ou seja, não está totalmente ainda bem adequado e estruturado no sistema educacional (DANTAS, 2017). É preciso fomentar a sensibilização com a questão dos processos inclusivos na comunidade escolar e social sendo que os maiores atores são as pessoas com deficiência que lutam por maiores reinvindicações para fazerem cumprir os seus direitos de igualdade em qualquer espaço.

Santos e Dantas (2017) sugerem a criação de um espaço ou comunidade na internet pelos estudantes com deficiência para apresentar as suas dificuldades e respectivas soluções ou adequações para a 
Instituição de Educação Superior - IES. Falam da importância de disponibilizar materiais informativos sobre a realidade da pessoa com deficiência para os docentes e demais interessados no processo de inclusão social. Complementam acerca da importância de acompanhar o aluno com deficiência ao longo dos semestres e ir melhorando as adaptações pedagógicas. Neste aspecto, o NAAC da Universidade onde esta pesquisa foi realizada faz o acompanhamento dos alunos com PCDs ao longo dos semestres, disponibilizando os recursos necessários para que ocorram as devidas adaptações pedagógicas. O NAAC já realizou dois eventos sobre Inclusão e Acessibilidade, porém o baixo número de docentes que participaram fez com que tentassem estratégias diferentes para que temas sobre acessibilidade pudessem ser disponibilizados aos professores.

Penso que, dependendo da deficiência, muitas vezes compete ao próprio professor adaptar o material didático utilizado em aula o que acarreta uma sobrecarga de trabalho ao professor, atividade realizada extra-classe. Penso que seria ideal haver um professor/monitor auxiliar para adaptar essas atividades e auxiliar na busca por materiais adaptáveis. [...] A sobrecarga de trabalho que muitas vezes gera a necessidade de adaptação de materiais de aula (para além daquilo que é ofertado pelo NAAC) e isso ser responsabilidade exclusiva do professor da disciplina (Professora 14).

Dantas (2017) afirma que as IES precisam se esforçar mais para eliminar as barreiras atitudinais que se refletem nas barreiras pedagógicas e de comunicação, o que interfere no processo de aprendizagem do estudante com deficiência. O mesmo autor complementa sobre a importância de políticas institucionais voltadas para a formação dos professores de modo a melhorarem as próprias práticas pedagógicas e assim conseguirem planejar os melhores recursos didáticos de acordo com as necessidades e peculiaridades de cada discente com deficiência.

Silva (2012) explica que somente com a erradicação das barreiras atitudinais e a prática efetiva do respeito dos direitos das pessoas com deficiência será possível vencer as barreiras sociais. De acordo com essa autora, as barreiras sociais podem ser eliminadas a partir da conscientização de que "todas as pessoas são iguais por pertencerem ao gênero humano e que as diferenças que as constituem são inerentes a esse gênero” (p. 425). Complementa ainda sobre a importância da tolerância e do afeto para conviver com todas as pessoas, não importando as suas crenças, ideais, fragilidades, habilidades, características físicas, dificuldades e competências.

Dentre as principais dificuldades encontradas, de acordo com os docentes, estão: o medo de enfrentar novos desafios; dificuldade de planejar o início do semestre, devido ao pouco tempo para adaptar o material pedagógico para o aluno com deficiência; o esquecimento de se direcionar ao aluno quando necessário, como, por exemplo, ficar no campo visual dos alunos com deficiência auditiva ou fazer a descrição visual para os que têm deficiência visual. Os docentes consideram que as adaptações são limitadas para alunos com deficiência, pois há falta ou pouca qualidade de recursos de acessibilidade, apesar de haver suporte do NAAC, é difícil produzir recursos novos rapidamente, além de as turmas serem grandes. 
Como sugestão de melhorias, de acordo com os professores pesquisados, seria importante uma política mais clara para inclusão nos cursos de graduação e na própria universidade. Isso implica em passar por um processo de humanização, superar os papéis cristalizados, estereótipos ou indefinições sobre as PCDs e trabalhar mais concretamente a partir de suas realidades. Outra sugestão é ter um professor/monitor para auxiliar na busca por materiais adaptáveis, além de usar diferentes estratégias de inclusão.

\section{CONSIDERAÇÕES FINAIS}

A proposta desta pesquisa foi conhecer a realidade dos docentes que lecionam para os estudantes com deficiência no Ensino Superior do interior do Rio Grande do Sul, de modo a propor possíveis sugestões de aperfeiçoamento pedagógico e promover um atendimento educacional especializado. Com base nas respostas fornecidas pelos docentes no questionário, foi possível identificar a existência de barreiras atitudinais por parte dos professores e o despreparo com os recursos pedagógicos.

Destacamos a baixa adesão dos professores na pesquisa, dos 98 convidados somente 19 se sentiram motivados a responder, apesar de a participação ser voluntária e anônima. Isso mostra que falta um maior incentivo por parte da gestão da universidade em melhorar a relação pedagógica entre professor e aluno com deficiência. Por outro lado, os poucos professores que responderam ao questionário se mostraram mais empenhados para melhorarem a relação com os seus alunos com deficiência, procurando vencer as barreiras atitudinais e as dificuldades de adaptações pedagógicas.

Os resultados dessa pesquisa mostraram algumas lacunas, sendo que uma das propostas de melhoria é a necessidade de expor e conscientizar o maior número possível de pessoas sobre a existência de várias barreiras atitudinais e uma reflexão diária sobre como vencer essas mesmas barreiras em todos os espaços da sociedade. Outra alternativa é promover a capacitação semestral ou anual com os professores do Ensino Superior, visando a uma conscientização sobre a existência de barreiras atitudinais e quais são as maneiras de lidar com isso de modo que não interfira no processo educativo de alunos com deficiência.

Outra sugestão de aperfeiçoamento é a criação de uma comunidade ou espaço na internet e de disponibilizar este espaço na página institucional de cada universidade. Dessa forma, será possível para os alunos com deficiência poderem apresentar as suas dificuldades e as respectivas soluções ou adequações, além de ser um espaço para disponibilizar materiais informativos sobre a realidade da pessoa com deficiência para os docentes e demais interessados no processo de inclusão social.

É evidente o esforço do NAAC em buscar alternativas viáveis por meio de ações inclusivas dos alunos que fazem parte desta universidade, conforme os relatos dos professores participantes que enfatizaram a importância do NAAC. Porém, o número elevado de professores que optaram por não 
participar voluntariamente dessa pesquisa talvez seja uma evidência de que precisa se discutir e problematizar mais sobre as políticas de inclusão.

\section{REFERÊNCIAS}

AMORIM, É. G.; MEDEIROS NETA, O. M.; GUIMARÃES, J. A deficiência em foco nos currículos de graduação da UFRN: uma abordagem histórica (1960-2015). Revista HOLOS [online], Instituto Federal do Rio Grande do Norte, ano 32, v.2, p. 231-248, mar. 2016. Disponível em:

<http://www2.ifrn.edu.br/ojs/index.php/HOLOS/article/view/4000>. Acesso em: 29 out. 2018.

BAHIA, D. C.; JANISSEK, J.; LOZADO, J. A. Metodologia científica aplicada: um guia prático para psicólogos. Salvador: Sanar, 2018.

BRASIL. Lei no 13.146, de 6 de julho de 2015. Institui a Lei Brasileira de Inclusão da Pessoa com Deficiência (Estatuto da Pessoa com Deficiência). Diário Oficial [da] República Federativa do Brasil, Brasília, DF, 06 jul. 2015. Disponível em: <http://www.planalto.gov.br/ccivil_03/_ato20152018/2015/lei/113146.htm>. Acesso em: 30 set. 2018.

BRASIL. Lei no 10.098, de 19 de dezembro de 2000. Diário Oficial [da] República Federativa do Brasil, Brasilia, DF, 20 dez. 2000. Disponível em:

<http://www.planalto.gov.br/ccivil_03/LEIS/L10098.htm>. Acesso em: 17 set. 2018.

CARVALHO, F. S. S. et al. Inclusão de Pessoas com Necessidades Especiais no Ensino Superior: desafios e perspectivas. Revista Diálogos e Perspectivas em Educação Especial, v.4, n.2, p. 53-62, jul./dez. 2017. Disponível em:

<file:///C:/Users/ADMIN/Downloads/7765-Texto\%20do\%20artigo-24972-1-10-

20180321\%20(3).pdf>. Acesso em: 25 abr. 2019.

DANTAS, N. M. R. A inclusão dos estudantes com deficiência no centro de formação de professores da Universidade Federal de Campina Grande: desafios e possibilidades. Biblioteca Digital de Teses e Dissertações, TEDE PUCRS, Porto Alegre, 2017. Disponível em:

$<$ http://tede2.pucrs.br/tede2/bitstream/tede/7838/2/Tese $\% 20-\% 20$ Noz $\% C 3 \%$ A2ngela $\% 20$ Maria $\%$ 20Rolim\%20Dantas.pdf>. Acesso em: 30 out. 2018.

FERNANDES, C. P.; SANTOS, A.; LAMARES, I. Intervenção psicoterapêutica com estudantes do ensino superior com Necessidades Educativas Especiais. In: Vieira (Org.). Apoio Psicológico no Ensino Superior: Um Olhar sobre o Futuro. Porto, Portugal. 2012. p. 310-319. Disponível em: $<$ https://www3.uma.pt/lsoares/LuisaSoares/Proceedings_files/Livro_Atas_RESAPES_2012.pdf>. Acesso em: 14 out. 2018.

FERRARI, M. A. L. D.; SEKKEL, M. C. Educação inclusiva no ensino superior: um novo desafio. Psicologia, ciência e profissão [online], Brasília, v.27, n.4, p. 636-647, dez. 2007. Disponível em: <http://www.scielo.br/pdf/pcp/v27n4/v27n4a06.pdf>. Acesso em: 08 out. 2018.

FLEITH, D. S. A política nacional de educação especial na perspectiva da educação inclusiva. In: GUZZO, R. S. L.; MARINHO-ARAÚJO, C. M. (Org.). Psicologia Escolar: identificando e superando barreiras. Campinas, SP: Editora Alínea, 2011. p. 33-46.

GERHARDT, T. E; SILVEIRA, D. T. Métodos de Pesquisa. Porto Alegre: Editora da UFRGS, 
2009.

GUERREIRO, E. M. B. R.; ALMEIDA, M. A.; FILHO, J. H. S. Avaliação da satisfação do aluno com deficiência no ensino superior. Avaliação: Revista da Avaliação da Educação Superior, Campinas, Sorocaba, SP, v. 19, n. 1, p. 31-60, mar. 2014. Disponível em:

http://www.scielo.br/pdf/aval/v19n1/03.pdf. Acesso em: 16 set. 2018.

MELO, F. R. L. V.; MARTINS, M. H. Legislação para estudantes com deficiência no ensino superior no Brasil e em Portugal: algumas reflexões. Acta Scientiarum. Education, Maringá, Portugal, v. 38, n. 3, p. 259-269, jul./set. 2016. Disponível em:

<http://periodicos.uem.br/ojs/index.php/ActaSciEduc/article/view/30491/17037>. Acesso em: 29 out. 2018.

MINAYO, Maria Cecília de Souza. O desafio do conhecimento: pesquisa qualitativa em saúde. 10. ed. São Paulo: HUCITEC, 2007.

NUNES, V. L. M.; MAGALHÃES, C. M. Gestão social na educação para pessoas com deficiência. Instituto Federal de Educação, Ciência e Tecnologia - HOLOS [online], Rio Grande do Norte, v. 32, p. 355-365, dez. 2016. Disponível em:

$<$ http://www2.ifrn.edu.br/ojs/index.php/HOLOS/article/view/3370/pdf>. Acesso em: 31 out. 2018.

SANTOS, P. K. DANTAS, N. M. R. Tecnologias assistivas e a inclusão do estudante surdo na educação superior. Revista Internacional de Educação Superior, Campinas, SP, v. 3, n. 3, p. 494514, set./dez. 2017. Disponível em:

$<$ https://periodicos.sbu.unicamp.br/ojs/index.php/riesup/article/view/8650620/16833>. Acesso em: 10 set. 2018.

SELAU, B.; DAMIANI, M. F.; COSTAS, F. A. T. Estudantes cegos na educação superior: o que fazer com os possíveis obstáculos? Acta Scientiarum. Education, Maringá, Portugal, v. 39, n. 4, p. 431-440, out./dez. 2017. Disponível em:

<http://periodicos.uem.br/ojs/index.php/ActaSciEduc/article/view/28915/20593>. Acesso em: 17 set. 2018.

SILVA, F. T. S. Educação Não Inclusiva: a trajetória das barreiras atitudinais nas dissertações de educação do Programa de Pós-graduação em Educação (PPGE/UFPE). Recife, UFPE, 2012.

Dissertação de Mestrado apresentada ao Programa de Pós-Graduação em Educação da Universidade Federal de Pernambuco, Recife, 2012. Disponível em:

<https://repositorio.ufpe.br/handle/123456789/12854?locale=pt_BR>. Acesso em: 27 abr. 2019.

SILVA, J. O. Ações inclusivas no ensino superior brasileiro. Rev. bras. Estud. pedagog. (online), Brasília, v. 95, n. 240, p. 414-430, maio/ago. 2014. Disponível em:

<http://www.scielo.br/pdf/rbeped/v95n240/09.pdf>. Acesso em: 25 abr. 2019.

SILVA, J. S. S.; FERREIRA, W. B. Sombreando a Pessoa com Deficiência: Aplicabilidade da Técnica de Sombreamento na Coleta de Dados em Pesquisa Qualitativa. Revista Brasileira de Educação Especial, Marília, v. 23, n. 2, p.185-200, abr./jun. 2017. Disponível em: <http://www.scielo.br/pdf/rbee/v23n2/1413-6538-rbee-23-02-0185.pdf>. Acesso em: 13 set. 2018.

SILVA, J. M.; SILVEIRA, E. S. Apresentação de trabalhos acadêmicos. Rio de Janeiro: Editora Vozes Ltda., 2007. 
SILVA, D. L; VINHA, M. L. Práticas Pedagógicas na Escola Inclusiva: Adaptação Curricular. Os Desafios da Escola Pública Paranaense na perspectiva do Professor PDE. Cadernos PDE (online), v.1, p.1-21, 2014. Disponível em:

<http://www.diaadiaeducacao.pr.gov.br/portals/cadernospde/pdebusca/producoes_pde/2014/2014_ uenp_edespecial_artigo_denise_lopes_da_silva.pdf>. Acesso em: 27 abr. 2019.

SILVA, F. T. S. Educação Não Inclusiva: a trajetória das barreiras atitudinais nas dissertações de educação do Programa de Pós-graduação em Educação (PPGE/UFPE). Recife, UFPE, 2012.

Dissertação de Mestrado apresentada ao Programa de Pós-Graduação em Educação da Universidade Federal de Pernambuco, Recife, 2012. Disponível em:

<https://repositorio.ufpe.br/handle/123456789/12854?locale=pt_BR>. Acesso em: 27 abr. 2019.

SIQUEIRA, I. M.; SANTANA, C. S. Propostas de acessibilidade para a inclusão de pessoas com deficiências no ensino superior. Revista Brasileira de Educação Especial, Marília, v.16, n.1 jan./abr. 2010. Disponível em: <http://www.scielo.br/scielo.php?script=sci_arttext\&pid=S1413-

65382010000100010>. Acesso em: 29 out. 2018.

Recebido em: 13 de novembro de 2019. Aprovado em: 7 de abril de 2020. 